\title{
Analyzing the Impact of a State Concussion Law using an Autoregressive Integrated Moving Average Intervention Analysis
}

\section{Lihong Huang}

Fudan University

Lindsay Sullivan

National University of Ireland Galway

Jingzhen (Ginger) Yang ( $\nabla$ ginger.yang@nationwidechildrens.org )

Ohio State University https://orcid.org/0000-0003-4019-0999

\section{Research article}

Keywords: Concussion, Children, Intervention Time Series, ARIMA

Posted Date: August 20th, 2020

DOl: https://doi.org/10.21203/rs.3.rs-32581/v2

License: (c) (i) This work is licensed under a Creative Commons Attribution 4.0 International License.

Read Full License

Version of Record: A version of this preprint was published at BMC Health Services Research on September 24th, 2020. See the published version at https://doi.org/10.1186/s12913-020-05742-0. 


\section{Abstract}

Background: Existing studies analyzing the impact of state concussion laws have found an increase in concussion-related medical encounters post-law, in some instances, such increases were observed during the pre-law period due to a potential "spillover" effect. This study assessed the effects of Ohio's concussion law, while accounting for such a "spillover" effect, on the trends in monthly rates of concussion-related medical encounters in Medicaid insured children using autoregressive integrated moving average (ARIMA) analysis.

Methods: We analyzed claim data obtained from the Partners For Kids database, a pediatric accountable care organization in Ohio. Concussion-related medical encounters for Medicaid-insured children (ages 018 years) treated between April 1, 2008 to December 31, 2016 were selected and analyzed. We assessed pre- and post-law trends in concussion-related medical encounters using an ARIMA intervention model. We also used traditional regression methods to validate the study results.

Results: A total of 16,943 concussion-related medical encounters sustained by 15,545 unique patients were included. Monthly rates of concussion-related medical encounters significantly increased from 4.64 per 10,000 member months during the pre-law period to 6.69 per 10,000 member month in the post-law period $(P<0.0001)$. Three upward breaks in the monthly rates of concussion-related medical encounters were observed between 2009 and 2016, with two breaks observed during the pre-law period. Specifically, the increased breakpoint observed in July $2011(P=0.0186)$ was significantly associated with an estimated $7.3 \%$ increase (95\% Cl: $1.1-13.7)$ in the rate of concussion-related medical encounters. This finding was confirmed in the Poisson regression and curve fitting models. Furthermore, a seasonal trend in concussion-related medical encounters was observed with the highest rates in September and October of each year.

Conclusions: Two of the three upward breaks identified in the monthly rate of concussion-related medical encounters occurred before the enactment of Ohio's concussion law, suggesting a potential "spillover" effect. Further research is needed to confirm such an effect in children with other types of medical insurance.

\section{Background}

Concussion, representing the immediate and transient symptoms of traumatic brain injury (TBI), is a form of mild TBI caused either by a direct blow to the head, face, neck or a blow elsewhere on the body with an impulsive force transmitted to the head [1-3]. Roughly 4,000 concussions are sustained daily by US children aged $\leq 18$ years [4]. Concussions often result in the rapid onset of short-lived impairment of neurological function that appears to resolve spontaneously and could have potential long-lasting effects on one's physical, cognitive, emotional, and/or sleep health. Untreated or improperly managed concussions may contribute to functional impairments and other long-term, severe health consequences [4-6]. 
To address the growing concern about concussion among youth, in 2009, Washington State enacted the Zackery Lystedt Law, the first state-level legal intervention aimed to mitigate the potential negative health consequences of concussion [6,7]. By 2014, all 50 US states and the District of Columbia enacted similar state-level concussion laws. Most concussion laws include the following three core tenets: (1) concussion education for coaches, parents, and/or athletes; (2) immediate removal of an athlete from play when a concussion is suspected; and (3) written clearance from a health professional before an athlete can return to play [8-10].

Several recent studies have evaluated the impact of these laws on rates of concussion and concussionrelated medical encounters. These include studies that evaluated the pre- and post-law trends in concussion rates using data collected from a national representative sample of high school athletes [11] or that analyzed concussion-related emergency department (ED) visits based on electronic health records [12]. Results show significantly increased concussion rates and concussion-related medical encounters from pre-law to post-law and, in some instances, such increases were observed during the pre-law period $[7,12,13]$. Such increases are largely attributed to increased concussion recognition and reporting due to mandatory concussion education for coaches, parents, and/or athletes [6, 11-13]. Additionally, Gibson et al. examined differences in concussion-related medical encounters between states with and without a concussion law using national insurance claim data and found significantly higher rates of concussionrelated medical encounters in states with a law as compared to states without a law $(P<.01)$ [6]. Interestingly, Gibson et al. observed a $75 \%$ overall increase in rates of concussion-related medical encounters during the study period among states without a law. Possibly, these observed outcomes (rates of concussion and concussion-related medical encounters) in states without a concussion law were due to "spillover" effects of other states' concussion laws. However, a paucity of research has accounted for this potential "spillover" effect when analyzing the impact of state concussion laws.

\section{Autoregressive integrated moving average}

Unlike traditional regression analysis, autoregressive integrated moving average (ARIMA), a classic method of time series analysis either with or without intervention analysis, can be used to measure the effect of an external or exogenous intervention on a time series while accounting for a potential "spillover" effect [14]. While the ARIMA model has been widely used in other fields, such as economics $[15,16]$, agriculture [17], and tourism [18, 19], very few studies have used the ARIMA intervention model to assess the effects of concussion laws on rates of concussion or concussion-related medical encounters. Trojian et al. used ARIMA to evaluate the effects of Connecticut's concussion law on ED visits for sportsrelated concussion by high school athletes and found that the monthly rate of concussions treated in the ED increased from 2.5 to 5.9 cases from pre-law to post-law [7]. Zemek et al. used ARIMA to investigate annual and seasonal trends of rates of physician office and ED visits for pediatric concussion in Ontario between 2003 and 2013 [20]; results revealed a steep increase in concussion visit rates from 2010 onward. However, these studies were limited by the use of ARIMA to test the seasonal variation in concussion rates rather than to directly assess the effects of the policy intervention. 
The current study applies the ARIMA intervention model to (1) quantify the rates of concussion-related medical encounters over time from 2008 to 2016 (pre-and post-enactment of Ohio's concussion law) among Medicaid insured children aged $\leq 18$ years and (2) measure the effect of Ohio's concussion law on trends in monthly rates of concussion-related medical encounters from pre-law to post-law while accounting for the "spillover" effects of other state concussion laws. In addition, this study used traditional regression methods to validate the study results.

\section{Methods}

\section{Study data and population}

Data used for this study were obtained from the Partners For Kids (PFK) pediatric accountable care organization database which includes the date and type of medical encounter(s), diagnosis, procedure(s), medication(s), treating physician(s), and facilities [21, 22]. PFK contracts with Medicaid-managed care plans in 34 counties in central and southeast Ohio, providing healthcare to approximately 330,000 children aged 0 to 21 years. For this study, healthcare claims for concussion-related medical encounters by actively enrolled PFK members aged 0 to 18 years between January 1, 2008 and December 31, 2016 were analyzed. Visits to multiple medical providers in the same day were treated as one concussionrelated medical encounter.

Concussions were identified using the International Classification of Diseases, Ninth and Tenth Revisions, Clinical Modification (ICD-9-CM and ICD-10-CM) codes for concussion: 850.0, 850.1, 850.11, 850.12, $850.2,850.3,850.4,850.5,850.9$, and those beginning with S06.0 [6, 23]. Only patients with one or more of the above concussion codes were included in the analyses. Concussions with a co-occurring severe TBI diagnosis code(s) (2.8\%) were excluded.

To ensure accuracy of the initial concussion-related medical encounter, the study inclusion criteria were defined as follows: (1) an injury was sustained between April 1, 2008 and December 31, 2016, and (2) the patient was continuously enrolled in PFK for at least 30 days prior to the initial concussion-related medical encounter [22]. For patients with multiple concussion-related encounters, at least 90 days without a concussion-related encounter was required to denote unique injuries. This study was approved by the Institutional Review Board at the authors' primary institution.

\section{Outcomes of interest}

The main outcome was the trend in monthly rate of concussion-related medical encounters per 10,000 member months, calculated as the number of initial concussion-related medical encounters in a month divided by the total number of PFK members in that same month, and multiplied by 10,000.

\section{Time series analysis}


The Box-Jenkins ARIMA intervention time series analysis was used to quantify the impact of Ohio's concussion law on trends in the monthly rates of concussion-related medical encounters. Seasonal ARIMA models were specified to account for the inherent dynamics in the series, and were expressed as $(p, d, q)$ and $(P, D, Q)$. The $p, d$, and $q$ specified the order of the autoregressive, differencing, and moving average processes of the regular noise model, while $P, D$, and $Q$ corresponded to the parameters for the seasonality component [24]. A log transformation was applied to the monthly rates series to ensure the normality and homogeneity of variance of the residuals. The concussion law was treated as the intervention and coded as a binary variable $(0=$ pre-law, before April 26,$2013 ; 1=$ post-law, on and after April 26, 2013).

To analyze the time series of monthly rates of concussion-related medical encounters, we defined $S=12$, corresponding to 12 observations per year. We assessed stationarity and used plots of autocorrelation function (ACF) and partial autocorrelation function (PACF) to identify the six parameters in the model. Akaike Information Criterion (AIC) and Bayesian Information Criterion (BIC) were used to compare models; the optimal model was based on the lowest AIC and BIC values. The mean absolute percentage error (MAPE) was calculated to assess forecast accuracy and to select an optimum model; the lower the MAPE value the better data fit.

The Ljung-Box Portmanteau (or Q) was used to examine the randomness of residuals of the estimated model. We assessed the effect of the intervention by interpreting the coefficient $\beta$ for the indicator variable. The percent change in the post-law period was estimated as $\exp (\beta)-1$.

Additionally, we validated the results of the ARIMA model using both traditional Poisson regression and curve fitting models. We first estimated the monthly rate per 10,000 member months and rate ratio of concussion-related medical encounters by including two independent variables (pre- or post-law group and the dummy variable of month identification) in the Poisson models, with a pre-defined reference month (either April 2008 or April 2013). We then employed the traditional curve fitting method to assess the trends of yearly rates of concussion-related medical encounters, using the coefficient of determination $\left(R^{2}\right)$ to determine goodness of fit. Finally, we compared the results of the ARIMA intervention time series analysis to the findings from the two traditional methods. All data analyses were conducted using SAS 9.4 and the TSA and forecast packages in R statistical software [24, 25], as appropriate. A $P<0.05$ was considered statistically significant.

\section{Results}

\section{Monthly rates of concussion-related medical encounters}

During the study period, we identified a total of 16,943 unique concussions that were sustained by 15,545 unique patients. Of these, $63.1 \%$ occurred in males with an average age of 11.63 years $(S D=4.91)$. Table 1 presents the frequency of concussion-related medical encounters during the study period by month. The annual frequency of concussion-related medical encounters increased from 1,139 to 2,472 between 2009 
and 2016. The overall rate of concussion-related medical encounters during the study period was 5.58 per 10,000 member months, with rates significantly higher during the post-law period (6.69 per 10,000 member months) than the pre-law period (4.64 per 10,000 member months) $(P<0.0001)$.

\section{Trend analysis using ARIMA intervention model}

Results of the ARIMA intervention model $(0,1,1)(2,1,0)_{12}$ diagnostics showed that the models provided a good fit to the data. More than 90 models were tested under the auto.arima function in $\mathrm{R}$ forecast package; AIC values, BIC values and MAPE were calculated for the partial intervention ARIMA models that were close to the selected model. Model $(0,1,1)(2,1,0)_{12}$ had the lowest AIC, BIC, and MAPE $(-243.22$, -229.03 and 6.38, respectively) (see eTable 1 in Supplementary Material). The correlation values of the fitted model were not outside the $95 \%$ Confidence Interval $(\mathrm{Cl})$ limits, and the residuals errors were considered white noise (see eFigure 1), indicating that this model was appropriate. The Ljung-Box test found that the autocorrelation coefficients were not significantly different from zero ( $Q=22.51, P=0.43)$.

The monthly rates series had an upward trend between 2009 and 2015 (Figure 1). Three structural breaks were considered and tested: (1) February 2010, (2) July 2011, and (3) July 2013. As shown in Figure 2, the expected rate series in 2016 and 2017, based on the ARIMA model forecast, were matched well with the observed trend, except for June 2016. Although the expected rates in June 2016 were lower than the observed rates, they were still within the $80 \% \mathrm{Cl}$. The upward trends and forecast trends were not observed in 2016 or 2017. However, the seasonal trend remained, with September 2017 and October 2017 having the highest rates of concussion-related medical encounters.

\section{Potential "spillover" effects}

The increased breakpoint observed in July $2011(P=0.0186)$ was significantly associated with an estimated $7.3 \%$ increase (95\% Cl: 1.1-13.7) in rate of concussion-related medical encounters, after controlling for the law intervention, trends, and seasonal variation (Table 2). The results from the curve fitting model demonstrated that the polynomial curve model was a good fit in estimating the trend of yearly rates of concussion-related medical encounters, with the fitted curve showing that the yearly rates increased from 2009 onwards (i.e., during the pre-law period) (see eFigure 2). The Poisson model showed a significantly higher monthly rate of concussion-related medical encounters in September 2012 as compared to April 2013, with a rate ratio of $1.65(95 \% \mathrm{Cl}=1.38,1.99)$ (see eTable 2).

\section{Discussion}

To our knowledge, this study is the first to apply the ARIMA intervention time series analysis to evaluate the impact of Ohio's concussion law on rates of concussion-related medical encounters over time among Medicaid-insured children aged $\leq 18$ years. The ARIMA intervention time series model has several advantages over traditional time series analyses, including power, flexibility, and increased accuracy of predictions [26-29]. The findings suggest that the application of the ARIMA intervention time series analysis may be appropriate for explaining the effect of Ohio's concussion law on concussion-related 
medical encounters. Our results revealed an increase in the monthly rates of concussion-related medical encounters from pre- to post-law, with two of the three upward breaks in the monthly rate of concussionrelated medical encounters observed during the pre-law period. These results suggest that there was a potential "spillover" effect of other states' concussion laws on concussion-related medical encounters in Ohio. Our results also showed a seasonal trend in the rate of concussion-related medical encounters, with rates highest in September and October of each year. Such findings may provide more precise and detailed information on the impact and nature of effect of Ohio's concussion law on concussion-related medical encounters over time.

Although the traditional Poisson regression analysis could quantify rates ratio, comparing pre-law monthly concussion-related medical encounter rates to post-law rates, and the polynomial curve could describe the trend of yearly rates, these two traditional methods are limited by their ability to describe patterns of rate changes or forecast future trends of interest. ARIMA time series intervention analysis, on the other hand, has emerged as a standard statistical method to assess the impact of an intervention (i.e., a planned policy change) over time or in time series forecasting [19, 30, 31]. ARIMA time series intervention analysis has several advantages over traditional statistical methods (i.e., Poisson regression, a polynomial curve). These include that it is based on its own historical data [32] and the previous error terms for forecasting [33]; it allows for the identification and describing of temporal trends during the study period [34,35]; and it enables the monitoring and forecasting of future monthly or annual trends $[24,33,36]$. However, it is important to note that the ARIMA intervention model is just one alternative method available to researchers when evaluating the impact of a law or forecasting trends of an outcome(s) of interest. The decision to employ the ARIMA time series model or traditional statistical methods should be guided by both the research question and the data type and structure.

The ARIMA time series intervention analysis has been increasingly used in epidemiologic research in recent years to assess intervention or policy impact $[33,34,36]$. Prior research shows that this model can be successfully applied to examine temporal trends and predict the incidence of various infectious diseases and injuries. For example, Lin et al. [33] used the ARIMA model to forecast monthly injury mortality trends and found that this model could be successfully applied to predict injury mortality. Despite its strengths and successful application in other fields [17, 19, 28, 29, 32], this study is the first to use the ARIMA time series intervention analysis to assess the impact of concussion laws on rates of concussion-related medical encounters over time from pre-law to post-law. Our findings may not only further our understanding of the effect of concussion laws on concussion-related healthcare utilization but may have important implications for future public health law impact research.

Using ARIMA intervention time series analysis, we identified three upward breaks in the monthly rates of concussion-related medical encounters during the study period. Two of these breaks were observed before Ohio's concussion law went into effect. Such findings have not been previously reported; thus, further research is needed to confirm these findings. Possibly, the first identified break (February 2010) may have been influenced by the enactment of Washington State's concussion law (The Zackery Lystedt Law) in 2009. Since the enactment of the Zackery Lystedt Law, media attention on and public awareness 
of concussion and the potential short- and long-term health consequences throughout the US has increased dramatically, which may partially explain the first observed increase in concussion-related medical encounters in Ohio. The second increase in concussion-related medical encounters was observed in July 2011. By then, 34 states had signed a state concussion law, 25 of which had been enacted [37]. These results may reflect a positive spillover effect of concussion laws; the law intervention in other states may have affected rates of concussion-related medical encounters in Ohio, perhaps highlighting the widespread effectiveness and benefits of the law intervention [38]. Finally, while not significant, we observed another increase in rates of concussion-related medical encounters in July 2013, immediately following the enactment of Ohio's concussion law. As noted above, these three breaks may be the result of local and national policy efforts that aim to mitigate the potential negative consequences of concussion.

Consistent with previous research $[7,20]$, our results suggest a distinct seasonal trend in the rate of concussion-related medical encounters, with rates highest in September and October of each year. This finding was unsurprising given that American football is played during these months and prior research shows that American football has a high incidence of concussion as compared to other youth sports [39]. Although knowledge and awareness about concussion has increased in recent years in both athletes and non-athletes [11-13, 40], our findings, in line with others, suggest that additional preventive strategies (i.e., rule changes, reduction of player-to-player contact in practice sessions) aimed to mitigate the risk of concussion among youth athletes are needed $[10,11,40]$. These preventive strategies would be especially beneficial for youth athletes who play contact or collision sports such as American football, ice hockey, and soccer [11,39-41]. Identification and testing of such preventive strategies may reduce the incidence of concussion.

This study has several limitations that warrant attention. First, similar to most studies that investigate the effects of policy changes on health outcomes, the present study is ecological in design. Because individual-level exposure data were not available, we were unable to attribute the increased rate of concussion-related medical visits solely to the concussion law. It is possible that the observed changes in rates of concussion-related medical encounter were due to unobserved economic or environmental confounding variables; thus, our results should be interpreted with caution. In addition, the observed upward breaks and seasonal trend in the monthly rates of concussion-related medical encounters were largely driven by our data and the selection of model(s) and need to be further validated. Finally, our results were based on medical encounters among Medicaid-insured children in Ohio; thus, our results may not be generalizable across states and/or to youth with other types of insurance.

\section{Conclusion}

This study assessed the effect of Ohio's concussion law on concussion-related medical encounters among Medicaid insured youth and adolescents using the ARIMA intervention model. Results revealed an increase in monthly rates of concussion-related medical encounters during the study period, with two of the three upward breaks in the monthly rates of concussion-related medical encounters observed in the 
pre-law period. These findings suggest that there is a potential "spillover" effect of concussion laws in states without such laws. Our findings demonstrated that the ARIMA intervention model is a promising method to examine the effect of state concussion laws. Future studies should examine the effect of state concussion laws, including potential spillover effects and the effects of specific law element(s), on concussion-related medical encounters in youth and adolescents with other types of health insurance.

\section{Abbreviations}

AMRIMA: autoregressive integrated moving average; PFK: Partners For Kids; ACF: autocorrelation function; AIC: Akaike Information Criterion; BIC: Bayesian Information Criterion; MAPE: The mean absolute percentage error; PACF: Partial autocorrelation function.

\section{Declarations}

\section{Ethics approval and consent to participate}

The Institutional Review Board of the Nationwide Children's Hospital granted approval of waiver of informed consent for this research (IRB18-01171).

\section{Consent for publication}

Not applicable.

\section{Availability of data and materials}

The datasets used and/or analyzed during the current study are available from the corresponding author on reasonable request.

\section{Competing interests}

The authors declare that they have no conflict of interests.

\section{Funding}

This research work was supported by funding from the Centers for Disease Control and Prevention National Center for Injury Prevention and Control (Grant 3 R49 CE002106-05S1 to Dr Yang) as well as by funding from the National Natural Science Foundation of China (Grant 81903407 to Dr Huang). Neither Centers for Disease Control and Prevention nor National Natural Science Foundation of China had a role in the design of the study, in the collection, analysis and interpretation of data, or in writing the manuscript.

\section{Author's Contributors}


LH contributed to the study design, led the analysis and interpretation of study data, and was a major contributor to writing of the manuscript. LS contributed to the study design, interpretation of data, and writing of the manuscript. JY contributed to the study design, acquisition, analysis, and interpretation of data, and writing of the manuscript. All authors critically reviewed and revised the manuscript and approved the final manuscript.

\section{Acknowledgements}

Research reported in this publication was supported by the Centers for Disease Control and Prevention National Center for Injury Prevention and Control under Award 3 R49 CE002106-05S1and the National Natural Science Foundation of China under Award 81903407. The content is solely the responsibility of the authors and does not necessarily represent the official views of the Centers for Disease Control and Prevention or the National Natural Science Foundation of China. The authors thank Dr. Yongyue Wei from Nanjing Medical University, China, for his helpful comments on previous drafts of this manuscript. The authors wish to thank Partners For Kids, Nationwide Children's Hospital, in particular, we would like to thank Drs. Gilbert Liu, Ling Wang, and Charitha Gowda for their time and invaluable support to this study.

\section{References}

1. Menon, D.K., S. Karen, D.W. Wright, et al., Position statement: definition of traumatic brain injury. Arch. Phys. Med. Rehabil., 2010. 91(11): 1637-1640.

2. Thurman, D.J., C. Alverson, K.A. Dunn, et al., Traumatic Brain Injury in the United States: A Public Health Perspective. J head Trauma Rehabil, 1999. 14(6): 602-615.

3. McCrory, P., W. Meeuwisse, J. Dvorak, et al., Consensus statement on concussion in sport-the 5 th international conference on concussion in sport held in Berlin, October 2016. Br. J. Sports Med., 2017. 51(11): 838-847.

4. Marsh, A.M., D. Fraser, and J.P. Marsh, Management of concussion in the pediatric patient. J. Pediatr. Health Care, 2013. 27(6): 499-504.

5. Kinnaman, K.A., R.C. Mannix, R.D. Comstock, et al., Management of pediatric patients with concussion by emergency medicine physicians. Pediatr. Emerg. Care, 2014. 30(7): 458-461.

6. Gibson, T.B., S.A. Herring, J.S. Kutcher, et al., Analyzing the effect of state legislation on health care utilization for children with concussion. JAMA Pediatr., 2015. 169(2): 163-168.

7. Trojian, T., P. Violano, M. Hall, et al., The effects of a state concussion law on the frequency of sportrelated concussions as seen in two emergency departments. Injury epidemiology, 2015. 2(1): 2.

8. Concannon, L.G., Effects of legislation on sports-related concussion. Phys. Med. Rehabil. Clin. N. Am., 2016. 27(2): 513-527.

9. Bompadre, V., T.M. Jinguji, N.D. Yanez, et al., Washington State's Lystedt law in concussion documentation in Seattle public high schools. J. Athl. Training, 2014. 49(4): 486-492. 
10. Harvey, H.H., Reducing traumatic brain injuries in youth sports: youth sports traumatic brain injury state laws, January 2009-December 2012. Am. J. Public Health, 2013. 103(7): 1249-1254.

11. Yang, J., R.D. Comstock, H. Yi, et al., New and recurrent concussions in high-school athletes before and after traumatic brain injury laws, 2005-2016. Am. J. Public Health, 2017. 107(12): e1-e7.

12. Mackenzie, B., P. Vivier, S. Reinert, et al., Impact of a state concussion law on pediatric emergency department visits. Pediatr. Emerg. Care, 2015. 31(1): 25-30.

13. Marin, J.R., M.D. Weaver, D.M. Yealy, et al., Trends in visits for traumatic brain injury to emergency departments in the United States. JAMA, 2014. 311(18): 1917-1919.

14. Makridakis, S. and M. Hibon, ARMA models and the Box-Jenkins methodology. J. Forecasting, 1997. 16(3): 147-163.

15. Ariyo, A.A., A.O. Adewumi, and C.K. Ayo. Stock price prediction using the ARIMA model. in 2014 UKSim-AMSS 16th International Conference on Computer Modelling and Simulation. 2014. IEEE.

16. Contreras, J., R. Espinola, F.J. Nogales, et al., ARIMA models to predict next-day electricity prices. IEEE T. power syst., 2003. 18(3): 1014-1020.

17. Padhan, P.C., Application of ARIMA model for forecasting agricultural productivity in India. J. Agric. Soc. Sci., 2012. 8(2).

18. Lai, S.L. and W.-L. Lu, Impact analysis of September 11 on air travel demand in the USA. J. Air Transp. Manag., 2005. 11(6): 455-458.

19. Ray, M., V. Ramasubramanian, A. Kumar, et al., Application of time series Intervention modelling for modelling and forecasting cotton yield. Stat. Appl., 2014. 12(1-2): 61-70.

20. Zemek, R.L., A.M. Grool, D.R. Duque, et al., Annual and seasonal trends in ambulatory visits for pediatric concussion in Ontario between 2003 and 2013. J. Pediatr., 2017. 181: 222-228. e2.

21. Gleeson, S., K. Kelleher, and W. Gardner, Evaluating a pay-for-performance program for Medicaid children in an accountable care organization. JAMA pediatr., 2016. 170(3): 259-266.

22. Tarimala A, Singichetti B, Yi HG. et al.. Initial emergency department visit and follow-up care for concussions among children with Medicaid. J Pediatr. 2019;206: 178-183.

23. Meehan, W.P. and R. Mannix, Pediatric concussions in United States emergency departments in the years 2002 to 2006. J. Pediatr., 2010. 157(6): 889-893.

24. Bisgaard, S. and M. Kulahci, Time series analysis and forecasting by example. 2011: John Wiley \& Sons.

25. Cryer J. , C.K., Time series analysis: with applications in R. 2 nd edn. 2008, New York: New York: Springer Science.

26. Pankratz, A., Forecasting with univariate Box-Jenkins models: Concepts and cases. Vol. 224. 2009: John Wiley \& Sons.

27. Chung, R.C., W. Ip, and S. Chan, Impacts of the overheating economy on China's manufacturing industry. Int. J. Adv. Manuf. Tech, 2009. 43(11-12): 1133. 
28. Mondal, P., L. Shit, and S. Goswami, Study of effectiveness of time series modeling (ARIMA) in forecasting stock prices. Int. J. Comput. Sci., Eng. and Appl., 2014. 4(2): 13.

29. Al Wadia, M. and M. Tahir Ismail, Selecting wavelet transforms model in forecasting financial time series data based on ARIMA model. Appl. Math. Sci., 2011. 5(7): 315-326.

30. Vujić, S., J.J. Commandeur, and S.J. Koopman, Intervention time series analysis of crime rates: The case of sentence reform in Virginia. Econ. Modelling, 2016. 57: 311-323.

31. Gilmour, S., L. Degenhardt, W. Hall, et al., Using intervention time series analyses to assess the effects of imperfectly identifiable natural events: a general method and example. BMC Med. Res. Methodol., 2006. 6(1): 16.

32. Lam, C.Y., W.H. Ip, and C.W. Lau, A business process activity model and performance measurement using a time series ARIMA intervention analysis. Expert Syst. Appl., 2009. 36(3): 6986-6994.

33. Lin, Y., M. Chen, G. Chen, et al., Application of an autoregressive integrated moving average model for predicting injury mortality in Xiamen, China. BMJ open, 2015. 5(12): e008491.

34. Linthicum, K.J., A. Anyamba, C.J. Tucker, et al., Climate and satellite indicators to forecast Rift Valley fever epidemics in Kenya. Science, 1999. 285(5426): 397-400.

35. Zhang, Y., Y. Zhang, and A. Haghani, A hybrid short-term traffic flow forecasting method based on spectral analysis and statistical volatility model. Transport. Res. C-Emer., 2014. 43: 65-78.

36. Sato, R.C., Disease management with ARIMA model in time series. Einstein (Sao Paulo), 2013. 11(1): 128-131.

37. Fjordbak, B.S., Protecting student athletes: growing number of states pass concussion-related legislation. The ASHA Leader, 2011. 16(10): 1-9.

38. Benjamin-Chung, J., J. Abedin, D. Berger, et al., Spillover effects on health outcomes in low-and middle-income countries: a systematic review. Int. J. Epidemiol., 2017. 46(4): 1251-1276.

39. Marar, M., N.M. Mcllvain, S.K. Fields, et al., Epidemiology of concussions among United States high school athletes in 20 sports. Am. J. Sport. Med., 2012. 40(4): 747-755.

40. Kerr ZY, Chandran A, Nedimyer AK, Arakkal A, Pierpoint LA, Zuckerman SL. Concussion Incidence and Trends in 20 High School Sports. Pediatrics. 2019;144(5):e20192180. doi:10.1542/peds.2019-2180

41. Patel DR, Yamasaki A, Brown K. Epidemiology of sports-related musculoskeletal injuries in young athletes in United States. Trans/ Pediatr. 2017;6(3):160-166. doi:10.21037/tp.2017.04.08.

\section{Tables}

Table 1. Number of concussion-related medical encounters by month, 2008-2016. 


\begin{tabular}{|c|c|c|c|c|c|c|c|c|c|}
\hline \multirow[t]{2}{*}{ Month } & \multicolumn{9}{|c|}{ Year } \\
\hline & 2008 & 2009 & 2010 & 2011 & 2012 & 2013 & 2014 & 2015 & 2016 \\
\hline January & - & 70 & 87 & 111 & 141 & 167 & 141 & 183 & 199 \\
\hline February & - & 68 & 70 & 93 & 147 & 130 & 143 & 175 & 177 \\
\hline March & - & 74 & 107 & 112 & 158 & 152 & 157 & 232 & 158 \\
\hline April & 80 & 111 & 105 & 109 & 177 & 179 & 194 & 205 & 217 \\
\hline May & 81 & 116 & 106 & 136 & 177 & 186 & 204 & 227 & 209 \\
\hline June & 75 & 73 & 84 & 122 & 149 & 126 & 140 & 129 & 121 \\
\hline July & 51 & 86 & 108 & 116 & 126 & 142 & 152 & 133 & 112 \\
\hline August & 94 & 115 & 137 & 195 & 232 & 241 & 270 & 276 & 227 \\
\hline September & 109 & 152 & 201 & 254 & 317 & 309 & 414 & 407 & 377 \\
\hline October & 111 & 113 & 182 & 199 & 243 & 356 & 387 & 312 & 339 \\
\hline November & 69 & 88 & 98 & 123 & 125 & 173 & 168 & 165 & 176 \\
\hline December & 56 & 73 & 64 & 111 & 125 & 150 & 188 & 146 & 160 \\
\hline Total & 726 & 1139 & 1349 & 1681 & 2117 & 2311 & 2558 & 2590 & 2472 \\
\hline
\end{tabular}

Table 2. Rate of concussion-related medical encounters per 10,000 member months from 2008-2016, integrated moving average (ARIMA) intervention models with three breakpoints

\begin{tabular}{|c|c|c|c|c|c|c|c|}
\hline \multicolumn{2}{|c|}{ Concussion Law Intervention Breakpoints } & \multicolumn{3}{|c|}{ Change } & \multicolumn{3}{|c|}{ ARIMA model and noise* } \\
\hline & & Percentage of Change & $95 \% \mathrm{CI}$ & $\mathrm{P}$ & Specification & Q24a & $\mathrm{P}$ \\
\hline Period 1 & Feb,2010 & 3.6 & -4.0 to 11.8 & 0.3628 & $(0,1,1)(2,1,0)_{12}$ & 20.13 & 0.58 \\
\hline Period 2 & July,2011 & 7.3 & 1.1 to 13.7 & 0.0186 & $(0,1,1)(2,1,0)_{12}$ & 21.70 & 0.48 \\
\hline Period 3 & July,2013 & 2.0 & -4.4 to 8.8 & 0.5449 & $(0,1,1)(2,1,0)_{12}$ & 22.70 & 0.42 \\
\hline
\end{tabular}

*The Ljung-Box Portmanteau (or Q-) test was used to test the randomness of residuals of the estimated models.

\section{Figures}




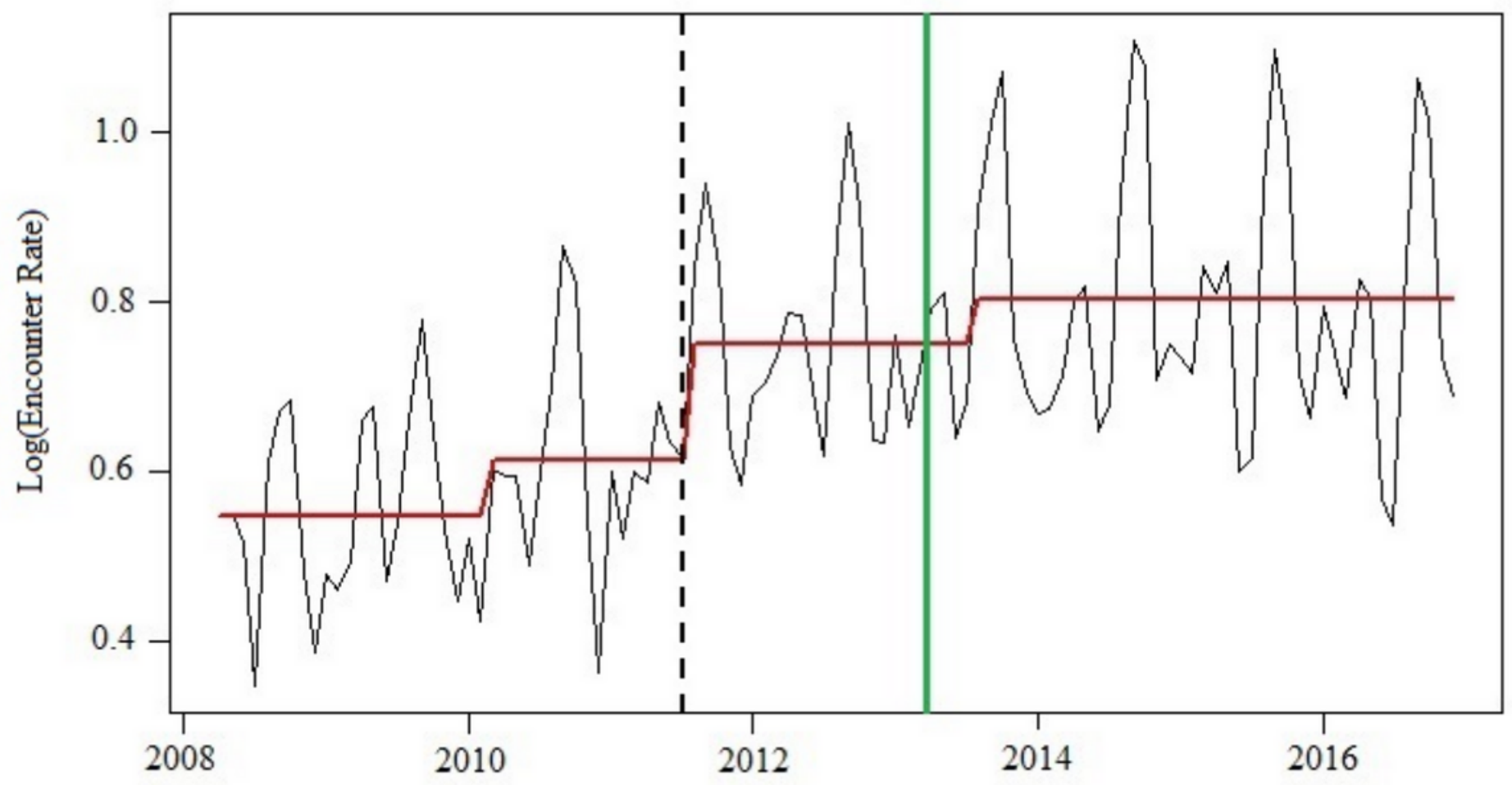

Figure 1

Three structural breaks in concussion-related medical encounter monthly rates series from 2008 to 2016 . (The dashline is the significant increase in breakpoints, the solid green line is the month in which the Ohio concussion law was enacted, and the red line is the fitted levels by the three identified breakpoints) 


\section{Forecasts from ARIMA $(0,1,1)(2,1,0)[12]$}

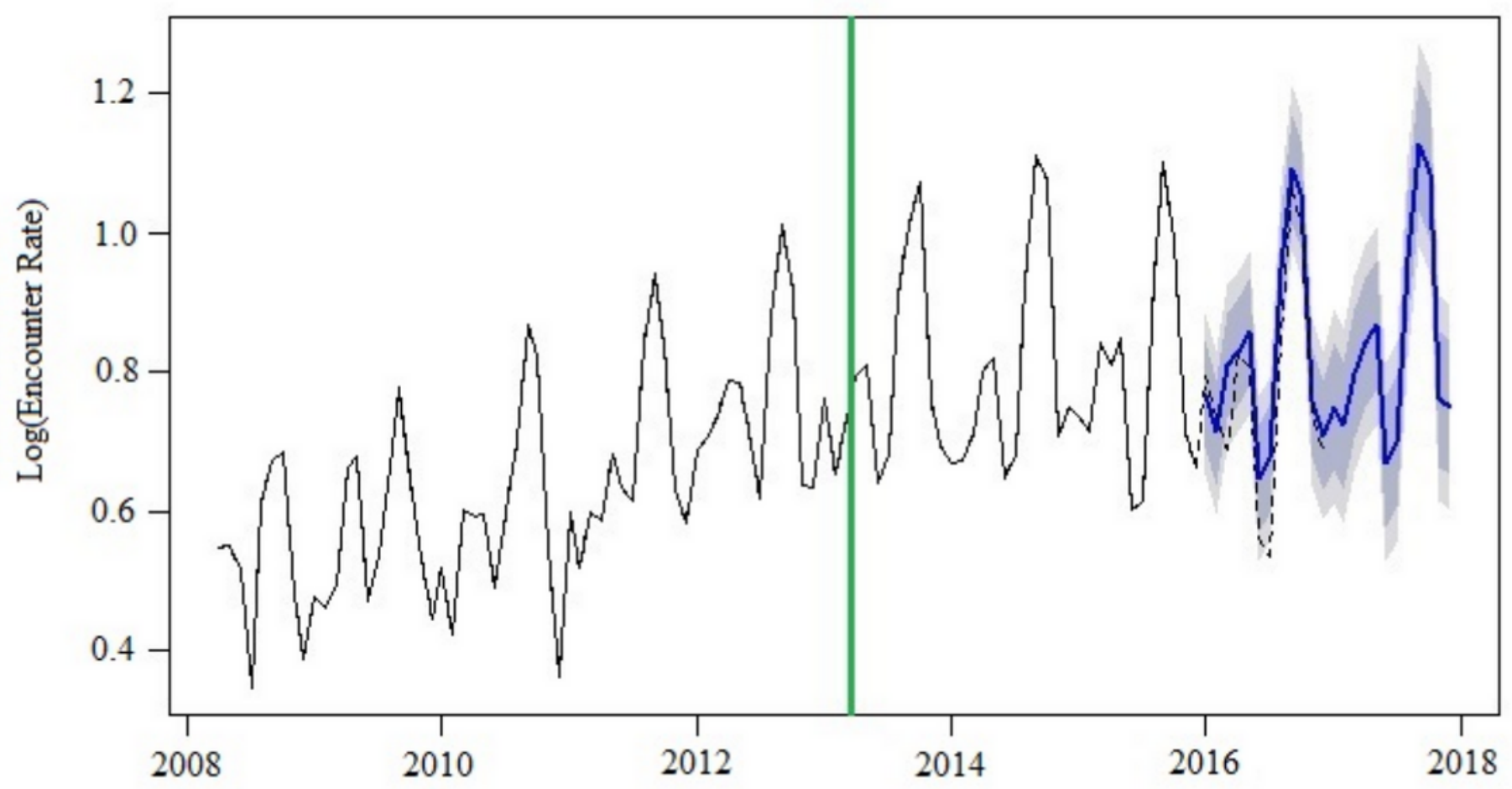

Figure 2

Forecasted 2016-2017 concussion-related medical encounters. (The solid blue line in 2016 and 2017 is the forecasted trend with $80 \%$ and $95 \% \mathrm{Cl}$, the dashed line in 2016 is the observed encounter rate, and the solid green line is the month is which Ohio's concussion law was enacted)

\section{Supplementary Files}

This is a list of supplementary files associated with this preprint. Click to download.

- SupplementaryMaterialAugust17.docx 